\title{
Effect of Nordihydroguaiaretic Acid on the Secretion of Lipoprotein Lipase
}

\author{
Sun-Mee Kim ${ }^{\dagger}$, Tae-Won Park ${ }^{\star}$ and Jin-Woo Park ${ }^{\dagger}, *$ \\ Department of Biochemistry and ${ }^{\ddagger}$ Psychiatry, Chonbuk National University Medical School, Jeonju 561-756, Republic of Korea
}

Received 25 July 2002, Accepted 28 August 2002

\begin{abstract}
Nordihydroguaiaretic acid (NDGA), an inhibitor of lipoxygenase, inhibits the secretion of proteins and causes the redistribution of resident Golgi proteins into the endoplasmic reticulum (ER). In this study, the effect of NDGA on lipoprotein lipase (LPL) secretion was investigated in 3T3-L1 adipocytes, and compared with those of brefeldin A (BFA), a well-known fungal metabolite that exhibits similar ER-Golgi redistribution. Both BFA and NDGA blocked secretions of LPL. In the presence of BFA, the active and dimeric LPL was accumulated in adipocytes. After endoglycosidase $\mathrm{H}$ (endo $\mathrm{H}$ ) digestion, the proportion of LPL subunits with partially endo $H$ sensitive oligosaccharide was significantly increased with BFA. However, in the presence of NDGA, the cellular LPL became inactive, and only the endo $\mathrm{H}$-sensitive fraction of the LPL subunit was observed. An increase of the aggregated forms was observed in the fractions of the sucrose-density gradient ultracentrifugation. These properties of LPL in the NDGA-treated cells were similar to those of LPL that is retained in ER, and the effects of NDGA could not be reversed by BFA. These results indicate that the inhibitory mechanism of NDGA on the LPL secretion is functionally different from the ER-Golgi redistribution that is induced by $B F A$.
\end{abstract}

Keywords: Brefeldin A, Lipoprotein lipase, Nordihydroguaiaretic acid, Protein secretion

\section{Introduction}

Lipoprotein lipase (LPL) is an acylglycerol hydrolase (EC 3.1.1.34) that hydrolyses the triacylglycerol component of lipoproteins into two fatty acids and monoacylglycerol for tissue utilization (Bensadoun, 1991). LPL plays a major role in triacylglycerol metabolism. Also, the deficiency or dysfunction of LPL has been found in association with the

*To whom correspondence should be addressed.

Tel: 82-63-270-3084; Fax: 82-63-274-9833

E-mail: jinwoo@moak.chonbuk.ac.kr pathogenesis of hypertriglyceridemia (Eckel, 1989). LPL has also been implicated to augment the uptake and degradation of lipoproteins, possibly by forming a bridge between the plasma lipoproteins and cell-surface receptors (Williams et al., 1992; Koo et al., 2000).

LPL is subject to regulation in a variety of physiological (feeding/fasting, cold adaptation, development, lactation, exercise) and pathophysiological (diabetes, obesity, endotoxin infection) situations (Eckel, 1989; Bensadoun, 1991). It follows then that LPL must be regulated by multiple factors that interact at various sites in the synthesis, processing, and translocation of LPL.

The production of active LPL by cells involves the following: the synthesis and N-linked glycosylation of lipase subunits in endoplasmic reticulum (ER), processing of oligosaccharide chains to make them endoglycosidase $\mathrm{H}$ resistant through ER and Golgi, dimerization of subunits, development of high affinity for heparin, acquisition of catalytic activity, and secretion (Masuno et al., 1991; Braun and Severson, 1992; Park et al., 1995; Park et al., 1996a; Park et al., 1997; Park, 2001). LPL in mouse adipocytes has two Nlinked oligosaccharide chains per subunit (Vannier and Ailhaud, 1989). Active LPL is known as a noncovalent homodimer. Dissociation of the dimer to the monomeric form renders the lipase inactive (Osborne et al., 1985). These maturation steps are important for the post-translational regulation of enzyme activity (Braun and Severson, 1992; Park et al., 1995; Scow et al., 1998).

Newly-synthesized secretory proteins are transported from the ER to the cell surface through the Golgi complex. The Golgi complex is comprised of structurally- and functionallydistinct subcompartments, which includes the cis-Golgi network, Golgi stack, and trans-Golgi network (TGN) (Rothman and Wieland, 1996). In the secretory pathway, the Golgi complex plays a key role in the sorting and modification of proteins. Resident ER proteins are sorted at the cis-Golgi network and recycled back to the ER through the KDELreceptors (Griffiths et al., 1994); lysosomal proteins are sorted at the TGN through the mannose-6-phosphate receptors (Kornfeld and Mellman, 1989). Modifications, such as oligosaccharide processing (Kornfeld and Kornfeld, 1985), 
proteolytic processing (Misumi et al., 1991), and sulfation (Hirose et al., 1988), are carried out by enzymes with specific localization in the Golgi compartments. Small vesicles that bud from a donor compartment and fuse with a target compartment membrane (Rothman and Wieland, 1996) mediate each transport step along the secretory pathway.

The use of drugs that affect the secretory process at specific sites in the cell may prove valuable for more detailed studies of the secretion steps, and may lead to an understanding of the molecular basis of the mechanisms that are involved in intracellular transport. One of the most useful and characterized drugs is the fungal metabolite brefeldin A (BFA). BFA strongly blocks secretion by inhibiting protein transport from the ER to Golgi (Misumi et al., 1986; Park et al., 1996a). It also causes redistribution of resident Golgi proteins into the ER (Doms et al., 1989; Lippincott-Schwartz et al., 1991).

Nordihydroguaiaretic acid (NDGA), a polyhydroxyphenolic antioxidant, exerts an inhibitory effect on the lipoxygenase pathways of arachidonic acid metabolism (Morris et al., 1979; Armour et al., 1981). NDGA also inhibits the secretion of prolactin from GH3 cells (Tagaya et al., 1993) and the intracellular transport of the vesicular stomatitis virus $G$ protein (Tagaya et al., 1996). Furthermore, NDGA rapidly disrupts the cisternal organization of the Golgi complex, and causes the redistribution of resident Golgi proteins into the ER, like the action of BFA (Drecktrah et al., 1998; Fujiwara et al., 1998).

BFA reportedly inhibits the secretion of LPL and causes the accumulation of active LPL in the redistributed ER-Golgi compartment (Park et al., 1996a). It also enabled the synthesis of active LPL from ER-retained inactive LPL via the translocation of Golgi components to ER (Park et al., 1996a). In this study, we investigated the effect of NDGA, another ER-Golgi protein redistributor (Drecktrah et al., 1998; Fujiwara et al., 1998), on LPL secretion in 3T3-L1 adipocytes. We demonstrated that ER-Golgi redistributions that are caused by BFA and NDGA were functionally different for LPL secretion.

\section{Materials and Methods}

Culture of 3T3-L1 cells The 3T3-L1 cells that were obtained from the American Type Culture Collection (ATCC CCL 92.1) were grown to confluence in 24-well culture plates with a standard medium (DMEM containing 10\% fetal bovine serum, $100 \mathrm{U} / \mathrm{ml}$ penicillin, $0.1 \mathrm{mg} / \mathrm{ml}$ streptomycin, and $0.25 \mu \mathrm{g} / \mathrm{ml}$ amphotericin B), as described by Park et al. (1997). Confluent cells were stimulated to differentiate into adipocytes by supplementing the standard medium with $1 \mu \mathrm{M}$ dexamethasone, $10 \mu \mathrm{g} / \mathrm{ml}$ insulin, and $0.5 \mathrm{mM}$ isobutylmethylxanthine for 2 days. The medium was then replaced with the standard medium that contained $5 \mu \mathrm{g} / \mathrm{ml}$ insulin and was changed every 2 days. The cultured cells were used for experiments within 5-6 days after confluence.

Assay of LPL activity At the end of experiment, the cells were rinsed with ice-cold phosphate-buffered saline (PBS), harvested with $0.5 \mathrm{ml}$ of a MNT-buffer $(20 \mathrm{mM} \quad 2$-(N-morpholino) ethanesulfonic acid, $100 \mathrm{mM} \mathrm{NaCl}, 30 \mathrm{mM}$ Tris- $\mathrm{HCl}$, and $1 \mathrm{mM}$ $\mathrm{CaCl}_{2}, \mathrm{pH}$ 7.6) that contained $1 \%$ Triton $\mathrm{X}-100$, and sonicated briefly at $4^{\circ} \mathrm{C}$. The suspension was centrifuged at $15,000 \times g$ for $20 \mathrm{~min}$ at $4^{\circ} \mathrm{C}$, and LPL activity in the infranatant was measured, as described by Park et al. (1997). Secreted LPL activity was determined from the medium.

A stock triacylglycerol emulsion that contained $5 \mathrm{mCi}$ of tri $\left[9,10(n){ }^{3} \mathrm{H}\right]$ oleoylglycerol (Amersham, Buckinghamshire, UK), 1.13 mmole of trioleoylglycerol, $60 \mathrm{mg}$ of 1- $\alpha$-phosphatidylcholine (bovine liver), and $9 \mathrm{ml}$ of glycerol was prepared according to the method of Nilsson-Ehle and Schotz (1976). Before assay, 1 vol. of the stock emulsion, 19 vol. of $3 \%$ bovine serum albumin (BSA) in $0.2 \mathrm{M}$ Tris-HCl buffer (pH 8.1), and 5 vol. of heat-inactivated fasted rat serum (heated at $60^{\circ} \mathrm{C}$ for $30 \mathrm{~min}$ ) were mixed and incubated for $30 \mathrm{~min}$. For assay, $100 \mu \mathrm{l}$ of this activated substrate mixture was added to the same amount of enzyme solution, and incubated at $37^{\circ} \mathrm{C}$ for $60 \mathrm{~min}$. Released fatty acids were extracted and its radioactivity was measured. One $\mathrm{mU}$ of LPL activity represents the release of 1 nmole of fatty acid/min.

Endoglycosidase $\mathbf{H}$ treatment and Immunoblotting of LPL The cell lysate was mixed with $1 \%$ SDS- $0.1 \mathrm{M}$ sodium citrate buffer (pH 5.5), boiled for $6 \mathrm{~min}$, and centrifuged at 3,000 $\times g$ for $10 \mathrm{~min}$. An aliquot of the supernatant was treated with endo- $\beta-\mathrm{N}$ acetylglucosaminidase $\mathrm{H}$ (endo H, Sigma Chemical Co. St. Louis, USA) as described previously (Park et al., 1997). Then $50 \mu \mathrm{l}$ of the supernatant was mixed with $5 \mu \mathrm{l}$ of $2 \%$ mercaptoethanol in $1 \mathrm{M}$ sodium citrate $(\mathrm{pH} 5.5), 5 \mu \mathrm{l}$ of protease inhibitor mix $(1 \mathrm{mg} / \mathrm{ml}$ aprotinin, $1 \mathrm{mg} / \mathrm{ml}$ leupeptin, $1 \mathrm{mg} / \mathrm{ml}$ antipain, and $10 \mathrm{mg} / \mathrm{ml}$ benzamide), and $3 \mu \mathrm{l}$ of $1 \mathrm{unit} / \mathrm{ml}$ endo $\mathrm{H}$. After incubation at $37^{\circ} \mathrm{C}$ for $24 \mathrm{~h}$, the reaction was stopped by the addition of an electrophoresis sample buffer $(62.5 \mathrm{mM}$ Tris- $\mathrm{HCl}, 2 \% \mathrm{SDS}, 5 \% 2-$ mercaptoethanol, $10 \%$ glycerol, $0.001 \%$ bromophenol blue, $\mathrm{pH}$ 6.8), and boiled for $5 \mathrm{~min}$.

LPL subunits in the mixtures were resolved with a $10 \%$ resolving and a 3\% stacking gel of SDS-PAGE (Laemmli, 1970), and transferred to a nitrocellulose membrane. The membranes were blocked with $2 \%$ BSA, and reacted with anti-bovine LPL chicken IgG (kindly supplied by Thomas Olivecrona in the Department of Physiological Chemistry, University of Umea, Umea, Sweden) overnight, and with alkaline phosphatase-conjugated anti-chicken IgG rabbit antiserum (Sigma Chemical Co., St. Louis, USA) for $2 \mathrm{~h}$. Color was developed in a BCIP/NBT solution.

Sucrose gradient ultracentrifugation The dimerization status of LPL was determined by sucrose-density ultracentrifugation, as described previously (Park et al., 1995). An aliquot of the cell lysate was mixed with sedimentation markers, bovine serum albumin (BSA, $M_{r}=65,400, \mathrm{~S}=4.1$ ), and yeast alcohol dehydrogenase $\left(M_{r}=150,000, \mathrm{~S}=7.6\right)$ (Park et al., 1995). Next, it was layered on top of a linear gradient of $5-20 \%(\mathrm{w} / \mathrm{v})$ sucrose in a MNT-buffer that contained $0.1 \%$ Triton $\mathrm{X}-100(3.6 \mathrm{ml})$ that was overlaid on $0.2 \mathrm{ml}$ of $40 \%$ sucrose. The samples were centrifuged at $300,000 \times g$ for $16 \mathrm{~h}$ at $4^{\circ} \mathrm{C}$ (Park et al., 1995), and the fractions of $0.3 \mathrm{ml}$ were collected from the bottom of the tube. Immunoblotting and activity assay for LPL were performed for each fraction. 


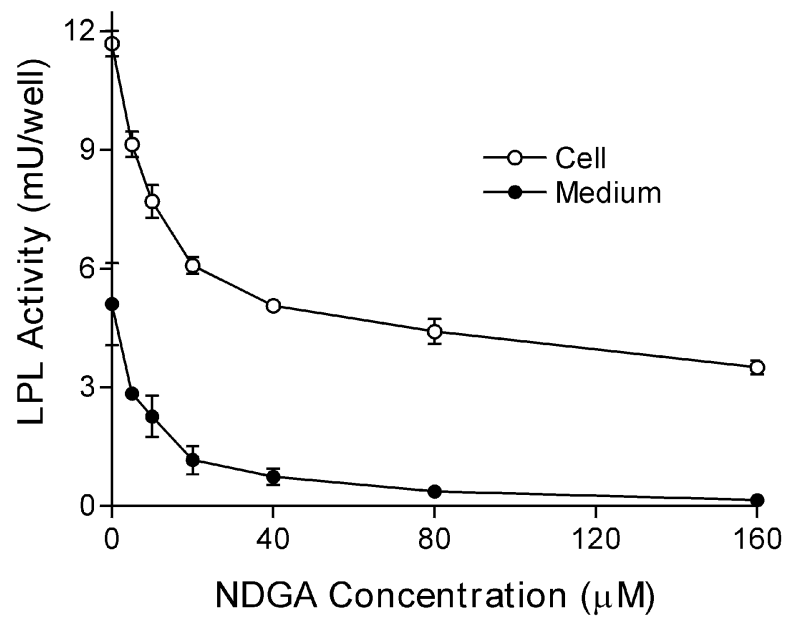

Fig. 1. Effect of NDGA on cellular and medium LPL activity in 3T3-L1 adipocytes. The 3T3-L1 adipocytes were incubated with $3 \mu \mathrm{g} / \mathrm{ml}$ heparin and $15 \mu \mathrm{M}$ cycloheximide for $2 \mathrm{~h}$ to deplete the existing cellular LPL. After washing with PBS, incubation was continued in the fresh medium for $4 \mathrm{~h}$ in the presence of various concentrations of NDGA. LPL activity was determined from the medium and cell lysate, as described in Materials and Methods. Data were expressed as the mean \pm S.E. of three separate experiments.

Lactate dehydrogenase (LDH) assay LDH was assayed with a cytotoxicity detection kit according to the manufacturer's instruction (Boehringer Mannheim, Mannheim, Germany).

\section{Results and Discussion}

Intracellular LPL was depleted by the incubation of 3T3-L1 adipocytes with $3 \mu \mathrm{g} / \mathrm{ml}$ heparin and $15 \mu \mathrm{M}$ cycloheximide for $2 \mathrm{~h}$. After washing with PBS, the cells were incubated in the presence of various concentrations of NDGA for $4 \mathrm{~h}$. Cellular and secreted LPL activities were decreased dosedependently by the NDGA treatment (Fig. 1). At $80 \mu \mathrm{M}$ of NDGA, cellular LPL activity decreased to $40 \%$ of the control, and no enzyme activity was detected in the medium. As a control without NDGA, LPL activity that was secreted into the medium began to increase linearly for $5 \mathrm{~h}$ (Fig. 2). NDGA significantly blocked the secretion of LPL within $1 \mathrm{~h}$, suggesting that the rapid reaction took place in the presence of NDGA.

At the concentration of $80 \mu \mathrm{M}$ NDGA, the cells were firmly attached to the plate and morphologically intact. The release of LDH into the medium was less than 5\% of the total cellular LDH contents, indicating that cytotoxicity of the drug was minimal (data not shown). In spite of no detectable LPL activity in the medium, a significant amount of the LPL protein was present in the cells that were incubated with NDGA for $4 \mathrm{~h}$ after the prior depletion of cellular LPL with heparin and cycloheximide. Considering the rapid turnover of the LPL protein (Bergo et al., 2002) and minimal cellular

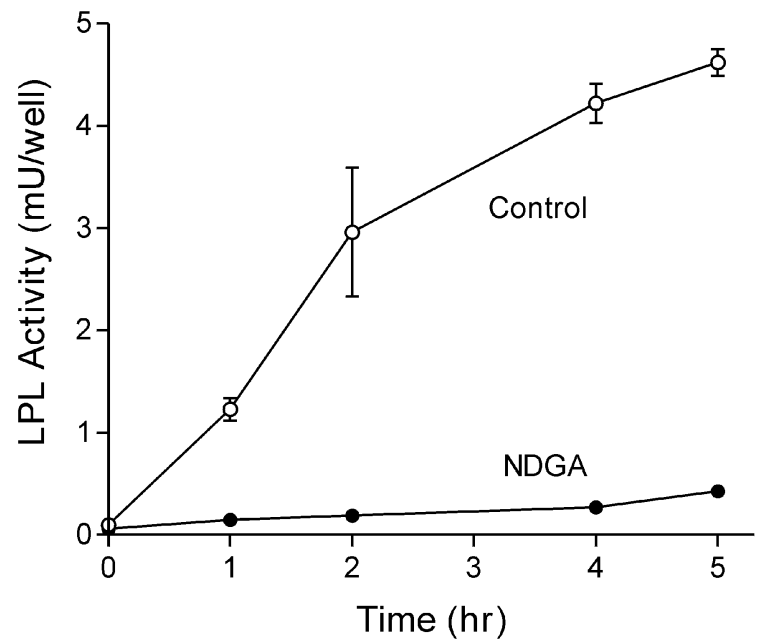

Fig. 2. Effect of NDGA on the medium LPL activity in 3T3-L1 adipocytes. The 3T3-L1 adipocytes were incubated with $3 \mu \mathrm{g} / \mathrm{ml}$ heparin and $15 \mu \mathrm{M}$ cycloheximide for $2 \mathrm{~h}$ to deplete the existing cellular LPL. After washing with PBS, incubation was continued in the fresh medium for the indicated times in the presence of $80 \mu \mathrm{M}$ NDGA. LPL activity was determined from medium, as described in Materials and Methods. Data were expressed as the mean \pm S.E. of three separate experiments.

damage under our experimental conditions, these results indicate that NDGA can inhibit the secretion, not the synthesis, of the LPL protein in 3T3-L1 adipocytes.

BFA is a well-known inhibitor of the protein secretion that causes the redistribution of resident Golgi proteins into ER through the retrograde transport (Misumi et al., 1986; Lippincott-Schwartz et al., 1991). Recently, NDGA was reported to have a similar ER-Golgi redistribution effect (Drecktrah et al., 1998; Fujiwara et al., 1998). As BFA and NDGA have no structural similarity, we tried to compare the effect of NDGA and BFA on the secretion of LPL in 3T3-L1 adipocytes.

When the cells were treated with $10 \mu \mathrm{g} / \mathrm{ml}$ BFA for $4 \mathrm{~h}$, no enzyme activity was detected in the medium, as with the NDGA treatment (Fig. 3). However, cellular LPL activity increased to $170 \%$ of the control by BFA treatment, in contrast to only $40 \%$ with NDGA. When both NDGA and BFA were present in the medium, cellular LPL activities were similar to those for the NDGA treatment.

Studies from adipocyte culture indicate that the production of active LPL involves the following: synthesis and $\mathrm{N}$ glycosylation of LPL subunits in ER, processing of endo $\mathrm{H}$ sensitive chains to endo H-resistant chains in the ER and Golgi, dimerization of subunits, acquisition of catalytic activity, and secretion (Masuno et al., 1991; Braun and Severson, 1992; Park et al., 1996a; Scow et al., 1998).

LPL in mice, rats, and humans has two N-linked oligosaccharide chains per subunit (Park et al., 1995; Park et al., 1996b). Three forms of LPL subunits were found after 


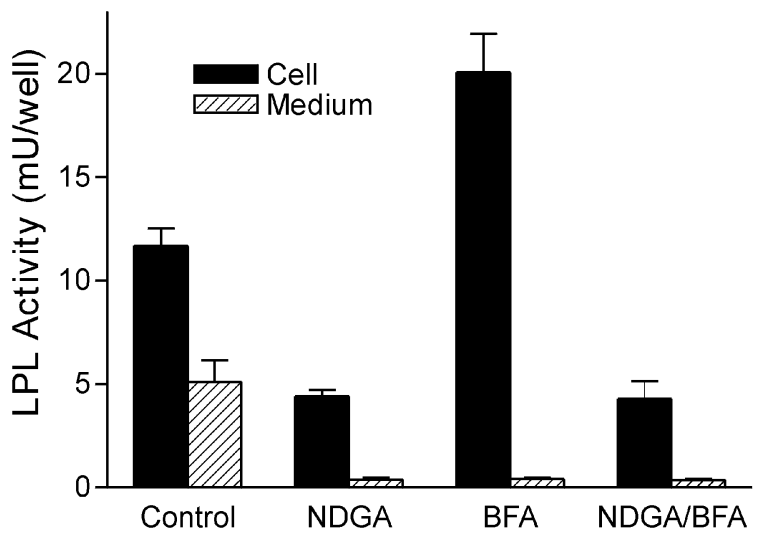

Fig. 3. Effect of NDGA and BFA on the cellular and medium LPL activity in 3T3-L1 adipocytes. The 3T3-L1 adipocytes were incubated with $3 \mu \mathrm{g} / \mathrm{ml}$ heparin and $15 \mu \mathrm{M}$ cycloheximide for $2 \mathrm{~h}$ to deplete the existing cellular LPL. After washing with PBS, incubation was continued in the fresh medium for $4 \mathrm{~h}$ in the presence of $80 \mu \mathrm{M}$ NDGA, $10 \mu \mathrm{g} / \mathrm{ml}$ BFA, or both. LPL activity was determined from the medium and cell lysate, as described in Materials and Methods. Data were expressed as the mean \pm S.E. of three separate experiments.

endo $\mathrm{H}$ digestion; endo $\mathrm{H}$ resistant, partially sensitive, and sensitive forms (Masuno et al., 1991; Park et al., 1995). Only the endo $\mathrm{H}$ resistant subunit that has the complex type chains at both sites are secreted and expressed on the cell surface (Vannier and Ailhaud, 1989). The endo H-sensitive subunit has the same molecular weight as the unglycosylated form (Masuno et al., 1991). The partially-sensitive form represents a kinetic intermediate that has one endo $\mathrm{H}$-sensitive and one endo H-resistant chain (Vannier and Ailhaud, 1989).

In ER, the glycosylation of LPL occurs during their transport across the ER membrane, and the trimming of three glucose and one mannose residue occurs from each oligosaccharide chain (Kornfeld and Kornfeld, 1985). The removal of those saccharide residues is essential for the subsequent transport to Golgi and the acquisition of activity. When the oligosaccharide-processing is blocked, then LPL is retained in ER. It has all of the endo-H sensitive, highmannose type chains.

NDGA and BFA effects on the processing of oligosaccharide were analyzed by the digestion of LPL with endo $\mathrm{H}$ and immunoblotting of LPL subunits. LPL that was contained in the normal 3T3-L1 adipocytes was composed of subunits that migrated on SDS-PAGE as a broad band of 56$57 \mathrm{kDa}$ (Fig. 4). After endo $\mathrm{H}$ digestion, three forms of LPL subunits appeared; endo H-resistant $(57 \mathrm{kDa})$, partially sensitive (54 kDa), and endo H-sensitive forms (51 kDa). BFA caused the absence of the endo H-resistant form and a great increase of the partially-sensitive $54 \mathrm{kDa}$ form. However, in the presence of NDGA, the $51 \mathrm{kDa}$ form was a major one, and the fractions of 54 and $57 \mathrm{kDa}$ were significantly decreased when compared to those of the control. This result is similar

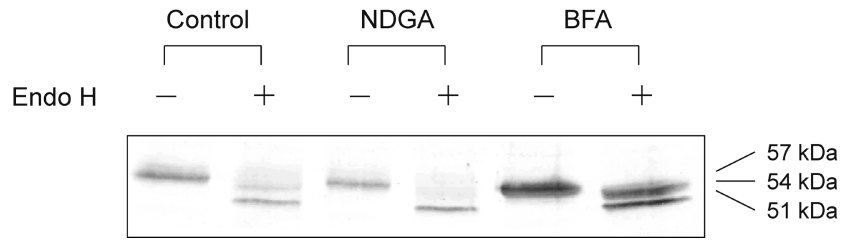

Fig. 4. Effect of NDGA and BFA on the glycosylation of LPL subunits in 3T3-L1 adipocytes. The 3T3-L1 adipocytes were incubated with $3 \mu \mathrm{g} / \mathrm{ml}$ heparin and $15 \mu \mathrm{M}$ cycloheximide for $2 \mathrm{~h}$ to deplete the existing cellular LPL. After washing with PBS, incubation was continued in the fresh medium for $4 \mathrm{~h}$ in the presence of $80 \mu \mathrm{M}$ NDGA or $10 \mu \mathrm{g} / \mathrm{ml}$ BFA. LPL in the cell lysate was digested with or without endo $\mathrm{H}$, and the LPL subunits were resolved by SDS-PAGE and immunoblotted. These findings are representative of 3-4 independent experiments.

to cells that contain ER-retained LPL (Park et al., 1995).

Normal adipocyte secretes an active, dimeric form of LPL. However, ER-retained LPL is inactive and forms aggregates (Masuno et al., 1991; Park et al., 1995). The effect of NDGA and BFA on the dimerization status of LPL was assessed using 5-20\% sucrose density-gradient ultracentrifugation. An aliquot of the cell lysate was centrifuged in the same tube with sedimentation markers, BSA (4.1S, $M_{r}$ 65,400), and yeast alcohol dehydrogenase (7.6 S, $M_{r}$ 150,000). After centrifugation, 12 fractions were collected from the bottom, and LPL activity in each fraction was determined. The LPL protein of each fraction was resolved by SDS-PAGE, and immunoblotted with the anti-LPL antibody.

In the control cells, most of the LPL proteins and activities were detected in the dimeric fractions (Fig. 5). Similar patterns were observed in the BFA-treated cells, indicating that the active, dimeric form of LPL was synthesized in the presence of BFA. In the presence of NDGA, while the dimeric form of LPL was dominant, a significant amount of LPL was observed in the bottom fractions. LPL activity was low, and detected only in the dimeric fractions.

In summary, BFA causes the production of active, dimeric LPL, as in the control cells; whereas, the accumulation in the large tubular and spherical structure that was formed by the redistribution of ER and Golgi (Park et al., 1996a) prevented the oligosaccharide processing to endo H-resistant. This resulted in an increase of the partially endo H-sensitive form. However, in the case of NDGA, the cellular LPL became inactive and only the endo $\mathrm{H}$-sensitive fraction of LPL subunit was observed. The fraction of the aggregated-form was increased with NDGA. These results indicate that the ERGolgi redistribution that is caused by NDGA is functionally different from that induced by BFA. The change of LPL properties that was induced by NDGA is rather similar to that of LPL that is retained in ER.

Furthermore, the NDGA effect could not be reversed by BFA (Fig. 3). In adipocytes that were treated with castanospermine, an inhibitor of ER glucosidase I, inactive 
$\begin{array}{llllllllllllll}\text { (A) } & \text { Fr.\# } & 1 & 2 & 3 & 4 & 5 & 6 & 7 & 8 & 9 & 10 & 11 & 12\end{array}$
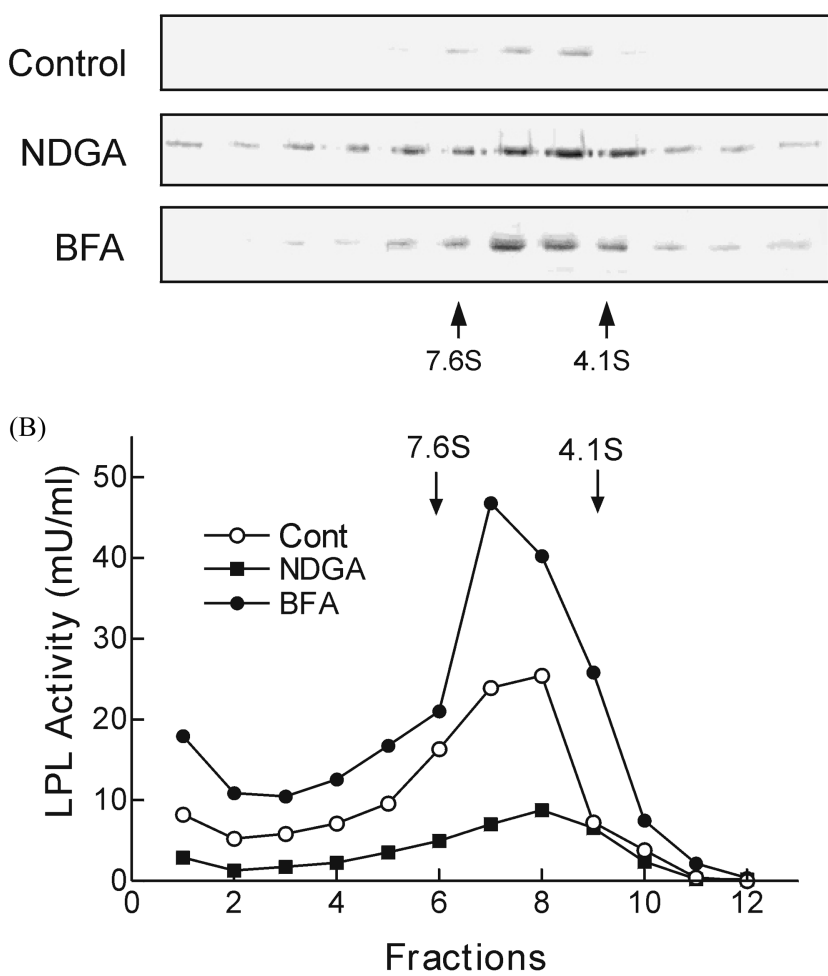

Fig. 5. Distribution of LPL protein (A) and activity (B) in sucrose gradient ultracentrifugation fractions of the control, NDGA, and BFA-treated 3T3-L1 adipocytes. The 3T3-L1 adipocytes were incubated with $3 \mu \mathrm{g} / \mathrm{ml}$ heparin and $15 \mu \mathrm{M}$ cycloheximide for $2 \mathrm{~h}$ to deplete the existing cellular LPL. After washing with PBS, incubation was continued in the fresh medium for $4 \mathrm{~h}$ in the presence of $80 \mu \mathrm{M}$ NDGA or $10 \mu \mathrm{g} / \mathrm{ml}$ BFA. The cell lysate was mixed with sedimentation markers and resolved by $5-20 \%$ sucrose gradient ultracentrifugation. After centrifugation, 12 fractions were collected from the bottom of the tube, and LPL protein was resolved by SDS-PAGE and immunoblotted (A). LPL activity in each fraction was determined, as described in Materials and Methods (B). Arrows indicate the fractions that contained the sedimentation marker, BSA $\left(4.1 \mathrm{~S}, M_{r} 65,400\right)$ and yeast alcohol dehydrogenase (7.6 S, $\left.M_{r} 150,000\right)$.

LPL was retained in ER with all the endo-H sensitive oligosaccharide chains (Masuno et al., 1991; Park et al., 1995). The addition of BFA to the castanospermine-treated adipocytes enabled the synthesis of active LPL and the processing of LPL subunits to partially endo H-resistance (Park et al., 1996a). Possibly, the Golgi enzyme, endo- $\alpha-D-$ mannosidase, provides the ER glucosidase-independent pathway for the formation of endo H-resistant oligosaccharides (Fujimoto and Kornfeld, 1991). However, in the case of NDGA, no increase of LPL activity was observed in the presence of BFA.

Our study demonstrated that the ER-Golgi redistribution that is caused by BFA and NDGA is functionally different from the LPL secretion. The action mechanism of BFA is known as the inhibition of the Golgi membrane-catalyzed GDP/GTP exchange of ARF, which results in the lack of formation of transport vesicles (Lippincott-Schwartz et al., 1990; Donaldson et al., 1992). The relevant molecular targets of NDGA are presently unknown, but recent work has implicated heterotrimeric G proteins in the NDGA-mediated disruption of Golgi morphology (Yamaguchi et al., 1997). In addition, NDGA is a phospholipase $\mathrm{A}_{2}$ and lipoxygenase inhibitor, which suggests a possible role for eicosanoids in regulating membrane trafficking (Tagaya et al., 1993). The exact action mechanism of NDGA on the inhibition of protein secretion requires further study.

\section{References}

Armour, C. L., Hughes, J. M., Seale, J. P. and Temple, D. M. (1981) Effect of lipoxygenase inhibitors on release of slowreacting substances from human lung. Eur. J. Pharmacol. 72, 93-96.

Bensadoun, A. (1991) Lipoprotein lipase. Annu. Rev. Nutr. 11, 217-237.

Bergo, M., Wu, G., Ruge, T. and Olivecrona, T. (2002) Downregulation of Adipose Tissue Lipoprotein Lipase during Fasting Requires That a Gene, Separate from the Lipase Gene, Is Switched On. J. Biol. Chem. 277, 11927-11932.

Braun, J. E. and Severson, D. L. (1992) Regulation of the synthesis, processing and translocation of lipoprotein lipase. Biochem. J. 287, 337-347.

Doms, R. W., Russ, G. and Yewdell, J. W. (1989) Brefeldin A redistributes resident and itinerant Golgi proteins to the endoplasmic reticulum. J. Cell Biol. 109, 61-72.

Donaldson, J. G., Finazzi, D. and Klausner, R. D. (1992) Brefeldin A inhibits Golgi membrane-catalysed exchange of guanine nucleotide onto ARF protein. Nature 360, 350-352.

Drecktrah, D., de Figueiredo, P., Mason, R. M. and Brown, W. J. (1998) Retrograde trafficking of both Golgi complex and TGN markers to the ER induced by nordihydroguaiaretic acid and cyclofenil diphenol. J. Cell Sci. 111, 951-965.

Eckel, R. H. (1989) Lipoprotein lipase. A multifunctional enzyme relevant to common metabolic diseases. N. Engl. J. Med. 320, 1060-1068.

Fujimoto, K. and Kornfeld, R. (1991) alpha-Glucosidase IIdeficient cells use endo alpha-mannosidase as a bypass route for $\mathrm{N}$-linked oligosaccharide processing. J. Biol. Chem. 266, 3571-3578.

Fujiwara, T., Takami, N., Misumi, Y. and Ikehara, Y. (1998) Nordihydroguaiaretic acid blocks protein transport in the secretory pathway causing redistribution of Golgi proteins into the endoplasmic reticulum. J. Biol. Chem. 273, 3068-3075.

Griffiths, G., Ericsson, M., Krijnse-Locker, J., Nilsson, T., Goud, B., Soling, H. D., Tang, B. L., Wong, S. H. and Hong, W. (1994) Localization of the Lys, Asp, Glu, Leu tetrapeptide receptor to the Golgi complex and the intermediate compartment in mammalian cells. J. Cell Biol. 127, 1557-1574.

Hirose, S., Oda, K. and Ikehara, Y. (1988) Tyrosine O-sulfation of the fibrinogen gamma $\mathrm{B}$ chain in primary cultures of rat hepatocytes. J. Biol. Chem. 263, 7426-7430. 
Koo, B. S., Lee, D. S., Yang, J. Y., Kang, M. K., Sohn, H. S. and Park, J. W. (2000) Lipoprotein-lipase-mediated uptake of glycated LDL. J. Biochem. Mol. Biol. 33, 148-154.

Kornfeld, R. and Kornfeld, S. (1985) Assembly of asparaginelinked oligosaccharides. Annu. Rev. Biochem. 54, 631-664.

Kornfeld, S. and Mellman, I. (1989) The biogenesis of lysosomes. Annu. Rev. Cell Biol. 5, 483-525.

Laemmli, U. K. (1970) Cleavage of structural proteins during the assembly of the head of bacteriophage T4. Nature 227, 680685 .

Lippincott-Schwartz, J., Donaldson, J. G., Schweizer, A., Berger, E. G., Hauri, H. P., Yuan, L. C. and Klausner, R. D. (1990) Microtubule-dependent retrograde transport of proteins into the ER in the presence of brefeldin A suggests an ER recycling pathway. Cell 60, 821-836.

Lippincott-Schwartz, J., Yuan, L., Tipper, C., Amherdt, M., Orci, L. and Klausner, R. D. (1991) Brefeldin A's effects on endosomes, lysosomes, and the TGN suggest a general mechanism for regulating organelle structure and membrane traffic. Cell 67, 601-616.

Masuno, H., Schultz, C. J., Park, J. W., Blanchette-Mackie, E. J., Mateo, C. and Scow, R. O. (1991) Glycosylation, activity and secretion of lipoprotein lipase in cultured brown adipocytes of newborn mice. Effect of tunicamycin, monensin, 1deoxymannojirimycin and swainsonine. Biochem. J. 277, 801809.

Misumi, Y., Miki, K., Takatsuki, A., Tamura, G. and Ikehara, Y. (1986) Novel blockade by brefeldin A of intracellular transport of secretory proteins in cultured rat hepatocytes. J. Biol. Chem. 261, 11398-11403.

Misumi, Y., Oda, K., Fujiwara, T., Takami, N., Tashiro, K. and Ikehara, Y. (1991) Functional expression of furin demonstrating its intracellular localization and endoprotease activity for processing of proalbumin and complement pro-C3. J. Biol. Chem. 266, 16954-16959.

Morris, H. R., Piper, P. J., Taylor, G. W. and Tippins, J. R. (1979) The effect of arachidonate lipoxygenase substrates and inhibitors on SRS-A release in the guinea-pig lung. $B r . J$. Pharmacol. 66, 452P.

Nilsson-Ehle, P. and Schotz, M. C. (1976) A stable, radioactive substrate emulsion for assay of lipoprotein lipase. J. Lipid Res. 17, 536-541.

Osborne, J. C., Jr., Bengtsson-Olivecrona, G., Lee, N. S. and Olivecrona, T. (1985) Studies on inactivation of lipoprotein lipase: role of the dimer to monomer dissociation. Biochemistry 24, 5606-5611.

Park, B. H. (2001) Inactive but dimeric form of lipoprotein lipase in human plasma. J. Biochem. Mol. Biol. 34, 329-333.

Park, J. W., Blanchette-Mackie, E. J. and Scow, R. O. (1996a) Brefeldin A enables synthesis of active lipoprotein lipase in cld/cld and castanospermine-treated mouse brown adipocytes via translocation of Golgi components to endoplasmic reticulum. Biochem. J. 317, 125-134.

Park, J. W., Lee, S. Y., Yang, J. Y., Rho, H. W., Park, B. H., Lim, S. N., Kim, J. S. and Kim, H. R. (1997) Effect of carbonyl cyanide m-chlorophenylhydrazone (CCCP) on the dimerization of lipoprotein lipase. Biochim. Biophys. Acta 1344, 132-138.

Park, J. W., Oh, M. S., Yang, J. Y., Park, B. H., Rho, H. W., Lim, S. N., Jhee, E. C. and Kim, H. R. (1995) Glycosylation, dimerization, and heparin affinity of lipoprotein lipase in 3T3L1 adipocytes. Biochim. Biophys. Acta 1254, 45-50.

Park, J. W., Yang, J. Y., Rhee, S. R., Cho, C. G., Park, B. H., Rho, H. W., Kim, J. S. and Kim, H. R. (1996b) Glycosylation of lipoprotein lipase in human subcutaneous lipomas. Horm. Metab. Res. 28, 7-10.

Rothman, J. E. and Wieland, F. T. (1996) Protein sorting by transport vesicles. Science 272, 227-234.

Scow, R. O., Schultz, C. J., Park, J. W. and Blanchette-Mackie, E. J. (1998) Combined lipase deficiency (cld/cld) in mice affects differently post-translational processing of lipoprotein lipase, hepatic lipase and pancreatic lipase. Chem. Phys. Lipids 93, 149-155.

Tagaya, M., Henomatsu, N., Yoshimori, T., Yamamoto, A., Tashiro, Y. and Fukui, T. (1993) Correlation between phospholipase A2 activity and intra-Golgi protein transport reconstituted in a cell-free system. FEBS Lett. 324, 201-204.

Tagaya, M., Henomatsu, N., Yoshimori, T., Yamamoto, A., Tashiro, Y. and Mizushima, S. (1996) Inhibition of vesiclemediated protein transport by nordihydroguaiaretic acid. $J$. Biochem. (Tokyo) 119, 863-869.

Vannier, C. and Ailhaud, G. (1989) Biosynthesis of lipoprotein lipase in cultured mouse adipocytes. II. Processing, subunit assembly, and intracellular transport. J. Biol. Chem. 264, 13206-13216.

Williams, K. J., Fless, G. M., Petrie, K. A., Snyder, M. L., Brocia, R. W. and Swenson, T. L. (1992) Mechanisms by which lipoprotein lipase alters cellular metabolism of lipoprotein(a), low density lipoprotein, and nascent lipoproteins. Roles for low density lipoprotein receptors and heparan sulfate proteoglycans. J. Biol. Chem. 267, 13284-13292.

Yamaguchi, T., Yamamoto, A., Furuno, A., Hatsuzawa, K., Tani, K., Himeno, M. and Tagaya, M. (1997) Possible involvement of heterotrimeric $\mathrm{G}$ proteins in the organization of the Golgi apparatus. J. Biol. Chem. 272, 25260-25266. 